in the dorsal and palmar view at wrist, MCP, PIP and DIP 2-5 joint levels for synovitis and tenosynovitis.

Subsequently, a comparison of the findings in the affected joints was performed using US as the reference method. Furthermore, AUC was calculated to show the extent to which a new joint inflammation was associated with a change in diagnosis.

Results: Of the 60 patients initially examined (1), 30 patients (dropout rate $50 \%$ ) were followed-up approximately 3 years later. The patients were newly divided into 3 groups: Diagnosed PsA ( $n=14$, Group I), still suspected PsA, ( $n=6$, Group II) and in-between diagnosed PsA ( $n=10$, Group III). Patients with a change in the diagnosis from suspected to diagnosed PsA (Group III) showed a significantly increased

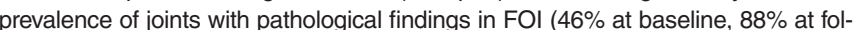
low-up; $p=0.046$ ), with an unchanged joint distribution pattern, i.e. with a dominant involvement of the DIP joints. Compared to baseline, patients of group III were three times more common to show enrichment in p3 in FOl at follow-up (1.7\% vs. $7.0 \%$; $\mathrm{p}=\mathrm{n}$.s.). Newly detected pathologic joints by FOI (PVM, p2) and US at follow-up were positively associated with the change of diagnosis from suspected PsA to confirmed PSA (FOI: AUC 0.78; GSUS: AUC 0.77). Using US in greyscale as reference, inflammatory changes in the joints were diagnosed in all 3 cohorts by means of FOI in P1 and P3 with high specificity (Group III: 90.6\%, Group II: 97.5\%, Group I: $94.2 \%$ ) and low sensitivity (Group III: $24.4 \%$, Group II: $20.3 \%$, Group I: $19.8 \%$ ).

Conclusion: FOI appears to be helpful to differentiate between acute and chronic disease stages. Furthermore, it is specific for detecting inflammatory changes in the joints of the hands in PsA - in comparison to US. FOI could thereby become a helpful tool as a "dermatological-screening" method to select psoriasis patients with indication for further rheumatological evaluation.

References:

[1] Zachariae H. Prevalence of Joint Disease in Patients with Psoriasis: Implications for therapy. Am J Clin Dermatol. 2003;4(7):441-447. Review.

[2] Erdmann-Keding M, Ohrndorf S, Werner SG, et al. Fluorescence optical imaging for the detection of potential psoriatic arthritis in comparison to musculoskeletal ultrasound. J Dtsch Dermatol Ges. 2019;17(9):913-921.

Disclosure of Interests: Juliane Büttner: None declared, Anne-Marie Glimm: None declared, Georgios Kokolakis: None declared, Magdalena Erdmann-Keding: None declared, Gerd Rüdiger Burmester Consultant of: AbbVie Inc, Eli Lilly, Gilead, Janssen, Merck, Roche, Pfizer, and UCB Pharma, Speakers bureau: AbbVie Inc, Eli Lilly, Gilead, Janssen, Merck, Roche, Pfizer, and UCB Pharma, Jens Klotsche: None declared, Sarah Ohrndorf: None declared DOI: 10.1136/annrheumdis-2020-eular.4823

\section{SAT0408 UTILITY OF CAROTID ULTRASOUND AND FRAMINGHAM RISK SCORE ON DISCRIMINATING CORONARY ARTERY DISEASE IN PATIENTS WITH PSORIATIC ARTHRITIS (PSA)}

I. T. Cheng ${ }^{1}$, K. T. Wong ${ }^{2}$, E. Li ${ }^{1}$, P. C. Wong ${ }^{2}$, B. T. L. Lai ${ }^{3}$, C. W. Yim³ ${ }^{3}$, S. K. Y. Ying ${ }^{4}$, K. Y. Kwok ${ }^{5}$, M. Li' ${ }^{1}$, T. K. Li ${ }^{1}$, J. J. W. Lee ${ }^{1}$, A. P. W. Lee ${ }^{1}$, L. S. Tam ${ }^{1}$ ${ }^{1}$ The Chinese University of Hong Kong, Hong Kong, Hong Kong (SAR); ${ }^{2}$ Prince of Wales Hospital, Hong Kong, Hong Kong (SAR); ${ }^{3}$ Tseung Kwan O Hospital, Hong Kong, Hong Kong (SAR); ${ }^{4}$ Princess Margaret Hospital, Hong Kong, Hong Kong (SAR); ${ }^{5}$ Queen Elizabeth Hospital, Hong Kong, Hong Kong (SAR)

Background: While carotid ultrasound (US) has been advocated for cardiovascular (CV) risk screening in patients with rheumatoid arthritis as various traditional scores underestimate $\mathrm{CV}$ risk, whether subclinical carotid atherosclerosis (SCA) is associated with coronary atherosclerosis on coronary computed tomography angiography (CCTA) in patients with psoriatic arthritis (PsA) remains uncertain. Objectives: This study aimed to identify carotid US parameters which can discriminate PsA patients with coronary artery disease (CAD) and obstructive CAD (O-CAD), and determine the utility in combination with Framingham Risk Score (FRS)

Methods: Ninety-one PsA patients (56 males; age: 50 \pm 11 years, disease duration: 9.4 \pm 9.2 years) without overt CV diseases were recruited. Carotid intima-media thickness (cIMT), presence of plaque and total plaque area (TPA) were determined by high-resolution US. CAD was defined as the presence of any coronary plaque on CCTA. O-CAD was defined as $>50 \%$ stenosis of the lumen. FRS $<10 \%$ indicates low CV risk, $10-19 \%$ indicates intermediate risk while $\geq 20 \%$ indicates high risk (1).

Results: Thirty-five (38\%) patient had carotid plaque. Fifty-five (60\%) patients had CAD and 9 (10\%) patients had O-CAD. $53(58 \%), 25(17 \%)$ and $13(14 \%)$ were classified as low, moderate and high $\mathrm{CV}$ risk according to the FRS respectively. FRS underestimated the CV risk as only $11 / 55(20 \%)$ of subjects with CAD were correctly identified as having high CV risk by FRS (Figure 1). Fifteen patients out of $53(28 \%)$ with low CV risk based on FRS were reclassified as high CV risk by the presence of carotid plaque. Nine out of these $15(60 \%)$ had CAD and 1/15 (6.7\%) had O-CAD. Concerning the carotid ultrasound parameters, CIMT (mean and maximum) and TPA were increased in both the CAD+ and $\mathrm{O}-\mathrm{CAD}+$ group compared to those without CAD or O-CAD (Table 1). Multivariate logistic regression analysis revealed that mean $\mathrm{CIMT}(\mathrm{OR}=1.06,95 \% \mathrm{Cl}: 1.01$ $1.11, p=0.013$ ) was an independent explanatory variables associated with $C A D$. Meanwhile, mean cIMT (OR=1.06, 95\%Cl: 1.01-1.11, $p=0.013)$ maximum cIMT (OR=1.06, 95\%Cl: $1.00-1.13, p=0.043)$, and TPA (OR=1.55, 95\%Cl: $1.01-2.36$ $p=0.043$ ) were independent explanatory variables associated with O-CAD after adjusting for covariates. Based on Receiver Operating Curve (ROC) analysis, an optimal cut off for $\mathrm{FRS}$ at $5 \%$ and mean cIMT at $0.62 \mathrm{~mm}$ yield $63 \%$ sensitivity and $73 \%$ specificity for the presence of CAD (AUC: $0.71, p=0.001$ ).

Table 1. Relationship between carotid ultrasound parameters and the presence and extent of coronary artery disease on coronary computed tomography angiography.

\begin{tabular}{|c|c|c|c|c|c|c|c|}
\hline \multirow[b]{3}{*}{ Mean carotid IMT, mm } & \multicolumn{6}{|c|}{ Coronary artery disease } & \multirow{3}{*}{$\begin{array}{c}p \\
0.017\end{array}$} \\
\hline & \multicolumn{3}{|c|}{ No $(n=37)$} & \multicolumn{3}{|c|}{ Yes $(n=54)$} & \\
\hline & 0.63 & \pm & 0.12 & 0.69 & \pm & 0.1 & \\
\hline Maximum carotid IMT, mm & 0.77 & \pm & 0.17 & 0.84 & \pm & 0.14 & 0.040 \\
\hline \multicolumn{8}{|l|}{ Carotid Plaque, n, \% } \\
\hline Absence & 26 & & $46.4 \%$ & 30 & & $53.6 \%$ & 0.156 \\
\hline Presence & 11 & & $31.4 \%$ & 24 & & $68.6 \%$ & \\
\hline \multirow[t]{3}{*}{ Total plaque area, $\mathrm{mm}^{2}$} & 0.0 & & {$[0,6]$} & 0.0 & & {$[0,10.8]$} & 0.059 \\
\hline & \multicolumn{6}{|c|}{ Obstructive coronary artery disease } & \\
\hline & \multicolumn{3}{|c|}{ No $(n=82)$} & \multicolumn{3}{|c|}{ Yes $(n=9)$} & $p$ \\
\hline Mean carotid IMT, mm & 0.65 & \pm & 0.12 & 0.76 & \pm & 0.07 & 0.011 \\
\hline Maximum carotid IMT, mm & 0.80 & \pm & 0.16 & 0.93 & \pm & 0.14 & 0.020 \\
\hline \multicolumn{8}{|l|}{ Carotid Plaque, n, \% } \\
\hline Absence & 53 & & $93.0 \%$ & 4 & & $7.0 \%$ & 0.235 \\
\hline Presence & 29 & & $85.3 \%$ & 5 & & $14.7 \%$ & \\
\hline Total plaque area, $\mathrm{mm}^{2}$ & 0.0 & & {$[0,7.0]$} & 6.0 & & {$[0,15.3]$} & 0.103 \\
\hline
\end{tabular}

IMT-intima media thickness; coronary computed tomography angiography.

Conclusion: Increased cIMT and TPA were associated with CAD and $\mathrm{O}-\mathrm{CAD}$ in PSA patients while the presence of carotid plaque alone was insufficient to discriminate patient with or without CAD. A combination of US parameters should be considered for CV risk stratification in patients with PsA.

References:

[1] Ford ES et al., J Am Coll Cardiol. 2004;43(10):1791-6.
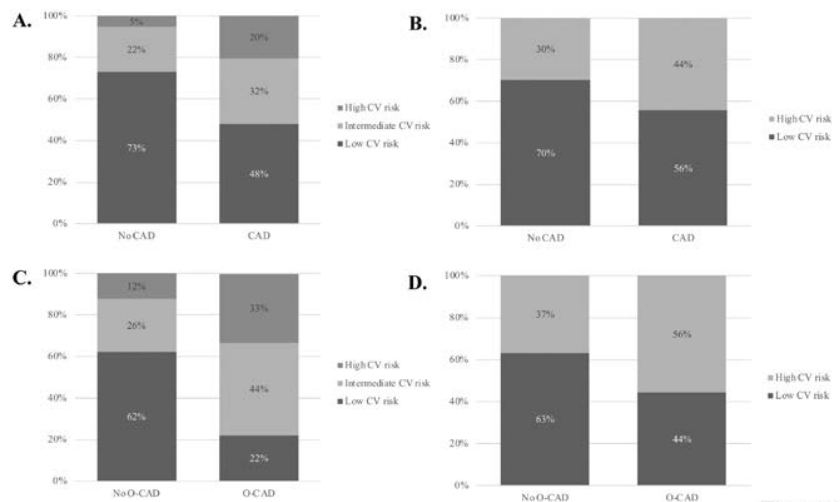

CV Risk classification based on Framingham risk score (FRS) (A\&C) (high CV risk: FRS $>20 \%$; CV Risk classification based on Framingham risk score (FRS) (A\&C) (high CV risk: $F R S \geq 20 \%$; intermediate C risk. $\mathrm{FS}$ risk $19 \%$, low $\mathrm{CV}$ risk. $\mathrm{RS}<10 \%$ ) and $\mathrm{CV}$ Risk classification based on the presence of carotid plaque

Disclosure of Interests: Isaac T. Cheng: None declared, Ka Tat Wong: None declared, Edmund Li: None declared, Priscilla C Wong: None declared, Billy Tin Lok Lai: None declared, Cheuk Wan Yim: None declared, Shirley King Yee Ying: None declared, Kitty Yan Kwok: None declared, Martin Li: None declared, Tena K. Li: None declared, Jack Jock Wai Lee: None declared, Alex Pui Wai Lee: None declared, Lai-Shan Tam Grant/research support from: Janssen, Pfizer, Novartis, Speakers bureau: Abbvie, Lilly, Sanofi

DOI: 10.1136/annrheumdis-2020-eular.3419

\section{SAT0409 \\ BIOLOGIC TREATMENT IN PSORIATIC ARTHRITIS AND AXIAL SPONDYLOPATHY REDUCES SICKNOTES ISSUED BY GPS, DESPITE DELAYS IN DIAGNOSIS: A REAL-LIFE STUDY IN WALES.}

E. Choy ${ }^{1}$, S. Brophy ${ }^{2}$, R. Cooksey ${ }^{2}$, L. Hanson ${ }^{3}$, A. Halliday ${ }^{4} .{ }^{1}$ Cardiff University, CREATE Centre, Section of Rheumatology, Cardiff, United Kingdom; ${ }^{2}$ Swansea University, Swansea, United Kingdom $;{ }^{3}$ Novartis Pharmaceuticals UK Limited, 